\title{
Application of Two-Valued and Fuzzy Logics Teaching in Understanding the Precise and Approximate Concepts
}

\author{
Mehraneh Delaviz Bayekolaei (Corresponding author) \\ Faculty of Education, Department Mathematics, University Malaya, Kuala Lumpur, Malaysia \\ E-mail: mehraneh.delaviz@yahoo.com \\ Norjoharuddeen Bin Mohd Nor \\ Faculty of Education, Department Mathematics, University Malaya, Kuala Lumpur, Malaysia \\ E-mail: norjo@um.edu.my \\ Reza Sohaei \\ Department of Management Lincoln University College Malaysia, Branch Iran \\ Abdul Karim Maleki Berneti \\ Education and Training District 2 Sari, Province Mazandaran, Iran \\ Romina Zerafat \\ Department of Management Lincoln University College Malaysia, Branch Iran \\ Hanieh Rasouli Saravi \\ Department of Management Lincoln University College Malaysia, Branch Iran
}

Received: 08-05- 2015

doi:10.7575/aiac.ijels.v.3n.3p.37
Accepted: 17-06-2015

URL: http://dx.doi.org/10.7575/aiac.ijels.v.3n.3p.37
Published: 31-07-2015

\begin{abstract}
This research aimed to examine the application of two-valued and fuzzy logics teaching in better understanding the precise approximate concepts of chapter 4 of Sixth grade mathematics. Participants of this study were 30 Sixth grade mathematics students from an elementary school in Sari (a city in the north of Iran) in the academic year of 2013-2014. Data were collected by a research-made 40 item questionnaire with close answers. The obtained information was analyzed based on a pre- and post-test by a paired-samples t-test. The results showed that teaching of propositional logic really does have influence on students' better understanding of the precise and approximate concept.
\end{abstract}

Keywords: Teaching, precise and approximate, sixth grade mathematics, two-valued and fuzzy logic

\section{Introduction}

The educational system has clearly announced that for researching to perfection, all humans can be guided towards their final goal by enjoying their natural and potential talents (The high council of Cultural Revolution and high council of education, 2011). Also, it was pointed that in document that curriculum system consists of four dimensions: planning, compiling, conducting and evaluating, which are all organized according to the" effective factors on quality" and goals of official and public education based on the history of civilization. Indeed, no civilization had been appeared unless it was strong in mathematics (Haddaa Adel, 1988). For Iran, mathematics is a key to get opportunities and to make up the past. Today, mathematics is not only a language of science, but also it has a direct effect on culture, economics, health and successful presence in international competitions (Bijan Zadeh, 2011). Mathematics provides the art of thinking for students and also makes them ready for a successful future. Our country needs a new attitude for development suggesting that workers, employees and all people should work more intelligently and increase their mental abilities. Here, our question is that how we should teach mathematics to realize its goals such as problem solving, correct guessing or correct approximating?

In this way, we can find the design and compilation of new educational methods in the form of an "Iranian -Islamic" ideational ground in such a 20 -item table in which thought, science, practice, belief and morals prepare the way for reaching self-identification, other-identification, creation-identification and to the final goal, which is the Creatoridentification. Also, it should be noted that despite some drawbacks of this table such as being floated of its different elements rather than being multiplicative, its advantages are so many that the researcher tried to present a new method based on several mentioned elements. Undoubtedly, authors of sixth grade mathematics textbook have done their best to present the practical usage of students' understanding about this book. Here, among eight chapters chapter 4 with the 
title of "Approximate Values" is one of the most applicable arguments in daily life which we use it consciously or unconsciously. So, considering to the importance of this subject such that students are able to use the precise and approximate concepts properly and logically, the researcher tries to compile and conduct a design by which we can fix this important subject in students' minds and actions.

One of the present problems in education is lack of students' interest in learning, particularly in some courses such as mathematics. The elementary stage is the foundation and basis of making students' scientific character and the ground of their positive or negative attitude towards these courses, particularly mathematics (Zameni \&Kardan, 2000). This is because the memorization of facts and procedures does not necessarily lead to students 'awareness of how and when to use their knowledge (Delaviz \& Leong, 2013). Hence, the suggested design for completing the precise and approximate teaching should be precise that not only doesn't make a negative attitude, but also provokes students' interest in applying the precise and approximate concepts in their daily life. It is challenging and sometimes very important as to whether the mentioned value in a numerical expression is a precise value or an approximate value. The textbook considers the importance of this subject, but its instructions are not enough due to different aspects of each expression. Therefore, the researcher tries to solve this problem partly by applying two-values and Fuzzy logics. Our question is that whether the influencing effect of them is effective or there are not any significant differences.

\section{Literature Review}

Despite the researchers' struggle to find some completely related backgrounds, there was not any. However, we can consider the following cases relatively related to our research. In a criticism on previous and present models, Zeraee Zavaraki (2012) introduced a new model in learning environment with a combined approach, and pointed out that the new models should enjoy combined approaches and a new and different in educational designing and learning environment. In a research, Jalali, Liaghatdar and Foroughi (2004) examined the effective factors on increasing the quality of mathematics teaching in the stage of Guidance school in Kara. Their results showed that increasing of teachers' abilities and students' motivating factors were effective on increasing the quality of mathematics teaching in Karaj's Guidance schools.

In a research, Kiamanesh and Noori (1998) found that in some countries such as Iran, there is too much attention to problem solving, but there is not any attention to "mathematical logic" and "establishing connection". In fact, with creating a positive attitude and a proper mental connection in students and by the help of educational aids, we can enjoy a more efficient and high-quality teaching and applying different skills in mathematics.

In a research with the title of "Guidance Students' attitude towards the reasons for these weakens in mathematics ", Asgharirad (1985) found that non-explanation of matters to students in the class is one of the reasons for students weakens in mathematics. In a research, Ball (1991) concluded that the reason of students' fear from mathematics may be resulted from teachers' un-interest, their lack of enough experience and knowledge about the objectives and vague and unclear concepts and strategies, and it does not relate to students' learning level .

Lockheed et al. (1986) analyzed data of the second studies on mathematics in Thailand for discovering the effect of textbooks and other factors on students' academic achievement in mathematics and concluded that whenever teachers use educational aids related to the subject, students' grades increase. In the course of several researches, Heyneman et al. (1981) examined the effect of textbooks and reading materials on motivation and positive learning attitudes in students and its effect on students' academic achievement in developing countries. They concluded that in addition to text book, other reading materials for effective and useful learning are very important. Before presenting research hypothesis and its methodology, we should define some terms.

\section{Propositional or Aristotle Logic}

It is also named as binary, black and withe, true or false, or zero-one logic (Ghayoumi, 2009). Aristotle logic is the basis of classic mathematics. Based on its principles, everything consist of only one fixed rule on which each case is true or false. In this research, teaching of propositional logic refers to presenting above rules with an understandable language to students in such a way that they know that there is not "between" in this logic. One thing is either zero or one and we do not have $\% 5$, or it is black or white and we do not have gray. In fact, propositional logic prefers fluency rather than accuracy.

\section{Fuzzy Logic}

Fuzzy logic was introduced by an Iranian professor, Lotfizadeh, in 1965. With a gray view towards the word, this logic shows the reality of facts completely and truly and brings it out of its definite black and white form (Noeeipour, 2006). The word of "Fuzzy "in Oxford means "chaotic "and totally it refers to concepts without a precise boundary. Fuzzy logic has a qualitative and multi-valued ambiguity (Ghagoumi, 2009).

Here, teaching of Fuzzy logic refers to explain this matter with a proper language to Sixth grade students in such a way that they know that some life matters cannot be zero or one, rather we have an infinite valued states between zero and one. One of the problems in using only information of Sixth grade mathematics in the case of identifying and distinguishing the precise and approximate expressions is that students mostly answer by chance. Therefore, in order to reach a reality by students for giving answers. The researcher tries to find whether these teachings help students to reach a certain definiteness in understanding the precise and approximate concepts with enjoying two-valued and fuzzy logics teachings and then analyzing the obtained results. So, the researcher collected data by designing the following model and presenting two hypothesis. 


\section{Research Hypotheses}

Based on of this study, the research hypotheses explored are as follows:

1- There is a significant difference in better understanding of the precise concept by sixth-grade students before and after teaching of propositional logic.

2- There is a significant difference in better understanding of the approximate concept by sixth-grade students before and after teaching of propositional logic.

\section{Methodology}

The method of this study was descriptive and survey based. In other words, the main design of this research has been based on pre-test and post-test and the considered intervention has been studied in an elementary school. The participants of this study were 30 Sixth grade students in an elementary school in Sari in the academic year of 20132014. Data were collected by a researcher-made questionnaire with close answers. The questionnaire consisted of 40 items with the precise or approximate expressions such that 20 items were related to the first hypothesis and 20 items were related to the second hypothesis which were organized randomly for preventing from answering by chance. In designing the questionnaire, we tried to use the theoretical principles of the precise and approximate concepts along with considering Propositional and Fuzzy logics. We used the views of some colleagues and experts for evaluating the formal and conceptual validity and we used Chronbach's alpha for determining the questionnaire's reliability. The calculated alpha was $\mathrm{a}=\% 74$ which showed an acceptable reliability. According to Leech, Barrett and Morgan (2008), a reliability coefficient of over 0.70 is favorable. Therefore, no further change was made in the questionnaire. After teaching the book's instructions about the precise and approximate concepts, we ran a pre-test and obtained the results. Then, our participants were taught propositional Fuzzy logic. Now, we ran a researcher -made post-test and the results were obtained. The distance between these two steps was 2 days. Teaching method was through conversation and slide shows. We used descriptive statistical methods, including mean and standard deviation for analyzing data. And also we used a paired-samples t-test for accepting or rejecting the studied hypothesis.

\section{Findings}

In order to examine whether there was any significant difference between the students' understanding of the approximate concept and precise concept before and after teaching of propositional logic, a paired-samples t-test was carried out.

First hypothesis: There is a significant difference in better understanding of the precise concept by sixth-grade students before and after teaching of propositional logic.

Table 1. Paired samples t-test results for the first hypothesis

\begin{tabular}{|c|c|c|c|c|c|}
\hline \multicolumn{6}{|c|}{ Paired Samples Statistics } \\
\hline & & Mean & $\mathrm{N}$ & $\begin{array}{c}\text { Std. } \\
\text { Deviation }\end{array}$ & $\begin{array}{l}\text { Std. Error } \\
\text { Mean }\end{array}$ \\
\hline \multirow[t]{2}{*}{$\begin{array}{l}\text { Pair } \\
1\end{array}$} & $\begin{array}{l}\text { precise } \\
\text { concept } 1\end{array}$ & 42.33 & 30 & 2.582 & 1.054 \\
\hline & $\begin{array}{l}\text { precise } \\
\text { concept } 2\end{array}$ & 43.83 & 30 & 2.563 & 1.046 \\
\hline
\end{tabular}

\begin{tabular}{|c|c|c|c|c|c|c|c|c|c|}
\hline \multicolumn{10}{|c|}{ Paired Samples Test } \\
\hline & & \multicolumn{5}{|c|}{ Paired Differences } & \multirow[t]{3}{*}{$\mathrm{t}$} & \multirow[t]{3}{*}{$\mathrm{df}$} & \multirow{3}{*}{$\begin{array}{l}\text { Sig. } \\
(2- \\
\text { tailed })\end{array}$} \\
\hline & & \multirow[t]{2}{*}{$\begin{array}{c}\text { Mean } \\
\text { difference }\end{array}$} & \multirow[t]{2}{*}{$\begin{array}{c}\text { Std. } \\
\text { Deviation }\end{array}$} & \multirow[t]{2}{*}{$\begin{array}{l}\text { Std. } \\
\text { Error } \\
\text { Mean }\end{array}$} & \multicolumn{2}{|c|}{$\begin{array}{l}95 \% \text { Confidence } \\
\text { Interval of the } \\
\text { Difference }\end{array}$} & & & \\
\hline & & & & & Lower & Upper & & & \\
\hline $\begin{array}{l}\text { Pair } \\
1\end{array}$ & $\begin{array}{l}\text { precise concept } \\
1 \text { precise } \\
\text { concept } 2\end{array}$ & -1.500 & .548 & .224 & -2.075 & -.925 & $\begin{array}{r}- \\
6.708\end{array}$ & 29 & .001 \\
\hline
\end{tabular}

A paired-samples t-test was conducted to compare understanding of the Precise Concept by sixth-grade students before and after teaching of propositional logic. There was a significant difference in the scores for before teaching of propositional logic $(M=42.33, S D=2.582)$ and after teaching of propositional logic $(M=43.83, S D=2.56)$; $t(29)=-6.708$, $\mathrm{p}=0.001$. These results suggest that teaching of propositional logic really does have influence on students' better understanding of the Precise Concept. Therefore, it can be concluded that there is a significant difference in Precise Concept scores at Time 1(Pre-test) and at Time 2(Post-test). 
Second hypothesis: There is a significant difference in better understanding of the Approximate Concept by sixth-grade students before and after teaching of propositional logic.

Table 2. Paired samples t-test results for the second hypothesis

\begin{tabular}{lllrrr}
\hline \multicolumn{5}{c}{ Paired Samples Statistics } & \\
\hline & Mean & $\mathrm{N}$ & \multicolumn{1}{c}{$\begin{array}{c}\text { Std. } \\
\text { Deviation }\end{array}$} & \multicolumn{2}{c}{$\begin{array}{c}\text { Std. Error } \\
\text { Mean }\end{array}$} \\
\hline $\begin{array}{l}\text { Pair } \\
1\end{array}$ & $\begin{array}{l}\text { approximate } \\
\text { concept 1 }\end{array}$ & 41.18 & 30 & 5.16 & .94 \\
\cline { 2 - 6 } & $\begin{array}{l}\text { approximate } \\
\text { concept 2 }\end{array}$ & 38.51 & 30 & 5.15 & .94 \\
\hline
\end{tabular}

\begin{tabular}{|c|c|c|c|c|c|c|c|c|c|}
\hline \multicolumn{10}{|c|}{ Paired Samples Test } \\
\hline & & \multicolumn{5}{|c|}{ Paired Differences } & \multirow[t]{3}{*}{$\mathrm{t}$} & \multirow[t]{3}{*}{ Df } & \multirow{3}{*}{$\begin{array}{l}\text { Sig. } \\
(2- \\
\text { tailed })\end{array}$} \\
\hline & & \multirow[t]{2}{*}{$\begin{array}{c}\text { Mean } \\
\text { difference }\end{array}$} & \multirow[t]{2}{*}{$\begin{array}{c}\text { Std. } \\
\text { Deviation }\end{array}$} & \multirow[t]{2}{*}{$\begin{array}{l}\text { Std. } \\
\text { Error } \\
\text { Mean }\end{array}$} & \multicolumn{2}{|c|}{$\begin{array}{l}95 \% \text { Confidence } \\
\text { Interval of the } \\
\text { Difference }\end{array}$} & & & \\
\hline & & & & & Lower & Upper & & & \\
\hline $\begin{array}{l}\text { Pair } \\
1\end{array}$ & $\begin{array}{l}\text { approximate } \\
\text { concept } 1 \\
\text { approximate } \\
\text { concept } 2\end{array}$ & 2.67 & 2.71 & .49 & 1.66 & 3.68 & 5.394 & 29 & .000 \\
\hline
\end{tabular}

A paired-samples t-test was conducted to compare understanding of the Approximate Concept by sixth-grade students before and after teaching of propositional logic. There was a significant difference in the scores for before teaching of propositional logic $(M=41.18, S D=5.16)$ and after teaching of propositional logic $(M=38.51, S D=5.15) ; t(29)=-5.394$, $\mathrm{p}=0.000$. These results suggest that teaching of propositional logic really does have influence on students' better understanding of the Approximate Concept. Therefore, it can be concluded that there is a significant difference in Approximate Concept scores at Time 1(Pre-test) and at Time 2(Post-test).

\section{Discussion and Conclusion}

According to the results of the first hypothesis, it is clear that teaching of propositional logic influences on understanding the Precise Concept by students. We did not find a completely related literature, but these results are connected with Asgharirad's (1985) which showed that one of the reasons for weakness of students in mathematics was non-explanation of matters for them in the class. Whenever some related information out of the textbook is stated along with instructions of the, textbook, students can learn and use them better. Also, our results are matched with the results of Kiamanish and Nouri research(1998) in which they concluded that there is not any attention to "mathematical logic "and "establishing connection "in mathematics books. Because, there is not any discussion about the precise or even approximate expressions and their scientific root. When student learn the scientific root and logical reasons based on their age and in the form of a good and new alphabet, such as Fuzzy and propositional logics, their motivation is provoked and the precise concept is understood better.

The results of the second hypothesis showed that teaching of Fuzzy logic influenced on understanding the Approximate Concepts by students. In this case, we did not find a completely related literature. But these results are relatively matched with the research results of Jalalis, Liaghatdar and Foroughiabri (2004), in which they referred to effect of increasing teachers' abilities and students' motivational factors on increasing the quality of mathematics teaching .Empowering by learning Fuzzy logic increases teachers' abilities on the one head, and the attractive name of Fuzzy logic along with its strong principles increases students' motivation and as result, increases teaching quality and learning of approximate concepts in mathematics of Sixth grade. In addition, these results are matched with results of Zaraee Zavaraki's research (2012) in which it was suggested that we should use combined approaches for presenting instructions in our new models. Because by using only instructions of the textbook, particularly in matters without enough certainly, and without combining a complementary matter, it is not certainly efficient. So our results showed that combining the textbook's with instructions of fuzzy logic to increase understudying the Approximate Concepts in Sixth grade mathematics was positive and effective.

\section{Recommendations}

Since one of the present concerns in education is structuring of a positive and correct mental structure and its establishment for applying in real world, it is hard to change these attitudes and concepts if they become fixed. As a result, if our teaching for a correct learning is not enough, the Sixth grade students who are in an important step in terms of age and education may learn incompletely the concepts and goals of the course book and then changing of this 
attitude will become hard. Therefore, taking these concerns and the obtained results into consideration, some recommendations could be presented for developing and applying of two-valued and fuzzy logics teaching in order to better understand the precise and approximate concepts as well as provide recommendations to other researchers:

1-Improvement of substructures of human forces and empowerment of Sixth grade teachers in the argument of Fuzzy and propositional logics by participating in workshops and in-service training;

2- Further research by analyzing the accuracy of these results by other statistical methods and samplings, such as test and retest, a large statistical universe, different genders (girls, girls and boys, along with other behavioral, educational and demographic components;

3-Supporting and employing some experts in the matter of propositional and Fuzzy logics and in designing software for full covering of the precise and approximate concepts; and

4-Making changes in curriculum of mathematics, particularly in the case of the precise and approximate concepts.

\section{Reference}

Asgharirad, S. (1985). The high school students' attitudes about the causes of weakness in math. Master's Thesis, Tehran, Faculty of IRIB.

Ball, A. D. (1991). Teaching Mathematics of understanding what Teachers Need to know about Subject Matter. Teaching Academic Subject to Diverse Learners. New York: Teacher college press.

Bisizan Zadeh, M. (2011). Teaching and learning of mathematics. Publication Noor, P, 5-7.

Delaviz, M., \& Leong, K.U. (2013). Exploring Students' Conceptual Understanding of Parallelograms Based on Geo Gebra. CoSMEd 2013 Penang, Malaysia 11 - 14 November 2013

Ghagoumi, X. (2009). Fuzzy logic and its philosophical foundations, a Master of Philosophy thesis, University of Madras.

Haddaa Adel, G. (1988). A report on the state of education in mathematics education. Journal of Mathematics Education, 18, 11-6.

Heyneman, S. (1981). Text books and Achievements in Developing Countries: What we know. Journal of Curriculum Studies, 13(3)-222-246.

Jalali, L., Liaghatdar, M., and Foroughi, A. (2004). Factors affecting the increase Quality of mathematics teaching high school in the Karaj. Journal of Planning Education and Research Program Course, 1, 21-42.

Kiamanesh, C. and Noori, D. (1998). The findings of the TIMSS Third International Mathematics Study Guide period. Tehran, Institute of Education

Lockheed,M., \& Vails, C., \& Fuller, B. (1986). Text books and Achievement in Developing Countries: Evidence from Thailand. Educational Evaluation and policy Analysis, 8(4), 379-392.

Leech, N. L., Barrett, K. C., \& Morgan, G. A. (2008). SPSS for intermediate Statistics: Use and interpretation. New

York, NY: Routledge.

Noeeipour, B. (2006). What is fuzzy logic? Network Magazine, 7.

---. (2011). The high council of Cultural Revolution and the high council of education, November, P 66-67.

Zameni,F and kardan, S. (2000). Application of ICT in learning mathematics. Journal of Information and Communication Technologies in Education, 1(1).

Zeraee Zavaraki, A. (2012). Teaching students with special education needs, based on universal principles of learning. Journal of Psychology of Exceptional p. (113). 